\title{
Culpa y responsabilidad como vertientes de la conciencia moral
}

\author{
ROBERTO R. ARAMAYO \\ Instituto de Filosofía del CSIC, Madrid
}

\begin{abstract}
RESUMEN. Si no estoy equivocado, nuestro acervo cultural nos hace asociar casi automáticamente a la culpa con un concepto religioso, de raigambre judeocristiana para ser más precisos, mientras que al mismo tiempo tiende a identificar la responsabilidad con una categoría eminentemente jurídica. La culpa se presenta como algo estrechamente vinculado con el pecado y la religión o, a lo sumo, con el psicoanálisis, en tanto que la responsabilidad suele circunscribirse de oficio al ámbito del derecho penal o relacionarse protocolariamente con la esfera política. Sin embargo, aunque las palabras «culpa» y «responsabilidad» no se prodiguen demasiado en los diccionarios consagrados a la ética, sí constituyen conceptos claves de la reflexión moral. Mi propósito aquí es presentarlos como dimensiones o vertientes complementarias de nuestra conciencia. Desde luego, cualquiera puede asumir una determinada responsabilidad sin sentirse culpable y, a la inversa, siempre hay quien prefiere regodearse con su sentimiento de culpabilidad sin sentirse responsable por la causa del mismo, pero lo suyo es que ambas nociones vayan de consuno y la culpa sea un síntoma de responsabilidad o que atender a las propias responsabilidades ahuyente cualquier asomo de culpabilidad por nuestra parte.
\end{abstract}

ABSTRACT. If I am not mistaken, our cultural baggage leads us almost automatically to associate guilt with a religious concept. To be more precise this has Judean-Christian roots. At the same time it also tends to lead to the identification of responsibility with strictly legal matters. Guilt is presented in close association with religion or, at most, with psychoanalysis, given that responsibility is usually restricted to criminal law or is associated in terms of protocol with politics. Nevertheless, although the words «guilt» and «responsibility» do not occur very often in dictionaries of ethics, they are key concepts in moral thought. My purpose here is to present them as dimensions or complementary aspects of our moral sense. It is of course possible for anyone to accept a specific responsibility without feeling guilty while, on the other hand, some people will always prefer to wallow in feelings of guilt without feeling responsible for the cause of the same. However, it is correct for both notions to work together with one accord. Guilt should therefore be a symptom of responsibility, while attending to our own responsibilities should be enough to ensure a complete lack of personal guilt. 
Allí donde mora la culpa ha de residir también la responsabilidad, siendo esto lo único que nos permite conjeturar la libertad moral.

(Schopenhauer, Los dos problemas fundamentales de la ética, E 94.)

¡Así de prodigiosa es la fuerza de la conciencia! Nos hace traicionarnos, acusarnos y combatirnos a nosotros mismos y, a falta de testigos extraños, nos descubre muy a pesar nuestro.

(Montaigne, Ensayos, II, 5.)

El itinerario que sugiero realizar aquí presenta cuatro hitos, los cuales coinciden con otros tantos autores, a saber, Immanuel Kant (1724-1804), JeanJacques Rousseau (1712-1788), Arthur Schopenhauer (1788-1860) y Denis Diderot (1713-1784). Dicho recorrido comienza por presentar la metáfora kantiana del tribunal de nuestra conciencia y luego examina el papel jugado por la culpa dentro del pensamiento de Rousseau, analizando después el planteamiento que Schopenhauer hace de la responsabilidad, para terminar con la evaluación de un caso práctico propuesto por Diderot.

\section{La metáfora kantiana del tribunal de la conciencia}

Por de pronto, en un autor que — según una opinión bastante generalizadatiene algo que ver con la filosofía moral, como es el caso de Kant, la palabra «responsabilidad» casi no aparece a lo largo de toda su obra, brillando más bien por su ausencia en su densa producción. Aunque no sea uno demasiado amante de tales estadísticas, debe reconocerse que a veces estos datos resultan cuando menos curiosos, cual sería el del caso que nos ocupa.

El término Verantwortlichkeit, el equivalente germánico de nuestra «responsabilidad», es usado una sola vez en los escritos kantianos. Para encontrarlo hay que acudir a La metafísica de las costumbres (1797) y prestar atención al $\S 13$ de la segunda parte. Allí se define Gewissenhaftigkeit, o sea, la «concienzudez» - habría que decir en castellano para expresar esa escrupulosidad propia de toda conciencia moral- «como responsabilidad ante un ente sagrado distinto de nosotros mismos, pero que nos representamos dentro de nuestro fuero interno y somete la propia voluntad a reglas de justicia, esto es, ante la razón que legisla moralmente» ${ }^{1}$. El agente moral kantiano debe rendir cuentas de su comportamiento ético ante sí mismo, en cuanto legislador autónomo de sus reglas morales, pues el hombre no conoce otro patrón para sus acciones que aquel ser divino albergado en su fuero interno con respecto al cual se compara y juzga, según señalaba Kant ya en su Crítica de la razón pura ${ }^{2}$.

1 Cfr. I. Kant, Metafisica de las costumbres, Ak. VI, p. 440.

${ }^{2}$ Cfr. I. Kant, Crítica de la razón pura, A 569, B 597. 
Esta suerte de divinidad interior, que Kant identificó en el opus postumum con la razón ético-práctica y autolegisladora ${ }^{3}$, cuenta con una instancia que vela por su buen hacer, y ésta no es otra cosa que la conciencia moral. En la Religión dentro de los límites de la simple razón (1793) Kant define a la conciencia moral de dos maneras. De un lado, nos dice Kant, la conciencia moral (Gewissen) equivale a una consciencia (Bewußtsein) que constituye un deber para sí misma ${ }^{4}$. Mas, de otro lado, la conciencia moral podría definirse también como el momento en que nuestra capacidad para juzgar moralmente se autoenjuicia o da en juzgarse a sí misma; con arreglo a esto, su tarea no sería tanto el juzgar si las acciones caen bajo la ley, pues ésta sería una labor propia de la razón práctica, sino comprobar si se ha tenido en cuenta dicho enjuiciamiento moral, invocando al hombre como testigo, a favor o en contra, de que tal cosa haya o no acontecido ${ }^{5}$.

Como es bien sabido, Kant compara todo esto con un proceso judicial y nos habla del tribunal de la conciencia. En sus Lecciones de Ética dice lo siguiente: «El tribunal interior de nuestra conciencia se asemeja en mucho a un tribunal de justicia ordinario. Dentro de nosotros nos encontramos con un fiscal que no podría ser tal de no existir una ley moral dada por la razón. De otro lado, también hallamos en el hombre a un abogado defensor, que no es otro sino el amor propio, el cual tiende a disculparle y a refutar las acusaciones objetando los alegatos del fiscal. Por último, encontramos asimismo en nosotros un juez que nos absuelve o condena. Este juez dictamina de un modo enteramente imparcial y su sentencia es inapelable» ${ }^{6}$. De hecho, según el Kant de la Metafísica de las costumbres (1797), «el ser consciente de un tribunal interno dentro del hombre - tribunal ante el cual sus pensamientos vienen a disculparse 0 acusarse recíprocamente-constituye la conciencia moral ${ }_{\gg}{ }^{7}$.

Desde luego, la idea del tribunal interior no es original de Kant y cuenta con una larga tradición. Michel de Montaigne, por ejemplo, aducía que, al ser los únicos espectadores de nuestra vida privada, «hemos de haber establecido en nuestro interior un modelo al que remitir nuestras acciones $y$, según él, acariciarnos o castigarnos. Tengo mis leyes y mi tribunal para juz- garme a mí mismo - escribió el autor de los Ensayos - y a ellos me atengo más que a cualquier otra cosa. Sólo vos sabéis si sois cobarde y cruel, o leal y devoto; los demás no os ven; os adivinan por conjeturas inciertas; no ven tanto vuestra naturaleza como vuestro arte» ${ }^{8}$.

${ }^{3}$ Cfr. I. Kant, Opus postumum, Ak. XXI, p. 145.

${ }^{4}$ Cfr. I. Kant, La religión dentro de los límites de la mera razón, Ak. VI, p. 182.

5 Cfr. op. cit., Ak. VI, 183.

- Cfr. I. Kant, Lecciones de ética, Roberto R. Aramayo y Concha Roldán (eds.), Barcelona, Crítica, 1988, pp. 71-72; Ak. XXVII.1, pp. 353-354. Cfr. R. R. Aramayo, Immanuel Kant. La utopía moral como emancipación del azar, Madrid, Edaf, 2001, pp. 169 ss.

7 Cfr. I. Kant, Metafísica de las costumbres, Ak. VI, p. 438.

${ }^{8}$ Cfr. M. de Montaigne, Ensayos, Dolores Picazo y Almudena Montojo (eds.), vol. III, cap. 2, Madrid, Cátedra, 1998, p. 30. 
La originalidad impresa por Kant a su metáfora del tribunal interior es el modo en cómo nos lo presenta. Según explica Kant en su Teoría de la virtud, todo hombre posee una conciencia moral y eso le hace ser observado por un juez interior que le sigue como su sombra; el hombre puede llegar a darle la espalda o no hacerle caso, pero jamás dejará de oír su temible voz. Ahora bien, como se trata de presentar un pleito, una causa, ante un tribunal, resulta bastante absurdo que tanto el juez como el acusado se identifiquen con una y la misma persona, pues bajo esas circunstancias el fiscal perdería siempre. Por ello, ante cualquier deber, la conciencia moral del hombre tendrá que pensarse como un alter ego distinto a uno mismo en cuanto juez de sus acciones. Este alter ego, añade Kant, podría ser un ideal creado por la razón, es decir, aquel ser divino al que nos referíamos hace un momento, el cual se identifica con la ley moral que nos otorgamos autónomamente a nosotros mismos. Por esa razón a Javier Muguerza le gusta subrayar que, dentro del tribunal de la conciencia descrito por Kant, «el sujeto moral no sólo es, además de "reo", "juez", sino también "legislador" o "autolegislador". Naturalmente, el sujeto moral no siempre se halla en situación de "inventarse" los contenidos de su moral, sino que dichos contenidos proceden normalmente de estos o aquellos "códigos morales" vigentes en su tiempo y en su sociedad; pero el sujeto moral siempre podrá asumirlos "autónomamente" si ésa es su voluntad» 9 .

Efectivamente, según Kant, al enfrentarse con el tribunal de su conciencia, el hombre desplegaría una doble personalidad, pues, por una parte, tiene que sentarse como acusado y temblar en el banquillo ante un tribunal al cual se confía él mismo, pero, por otra, tiene también encomendadas las funciones de juez merced a una connatural autoridad. Aunque bien mirado, en realidad el asunto es algo más complejo, si tenemos en cuenta que aparte de asumir los roles de acusado y juez, tiene que desempeñar asimismo los papeles de fiscal y de abogado defensor, sin dejar de oficiar en todo momento como legislador autónomo. Pero se diría que Kant otorga las funciones del defensor al acusado y confiere a ese legislador encarnado ahora en el juez las tareas del fiscal, cuando nos habla del mencionado desdoblamiento de personalidad.

«Esa doble personalidad necesita ser explicada - escribe Kant en $L a$ metafísica de las costumbres - , para evitar que la razón caiga en una contradicción consigo misma. Yo, acusador y acusado, soy el mismo hombre, pero en cuanto sujeto de una legislación moral, procedente del concepto de libertad, en la cual el hombre se halla sometido bajo una ley que se confiere a sí mismo, tiene que considerarse como un alter ego del hombre sensible dotado de razón, aunque sólo con respecto a lo práctico.» Este alter ego es quien oficia como fiscal acusador, frente al cual se autoriza la presencia de un ase-

9 Cfr. J. Muguerza, «El tribunal de la conciencia y la conciencia del tribunal», Doxa, núm. 1516, 1994, pp. 537-538. 
sor jurídico del acusado (su abogado defensor). Una vez concluida la causa, el juez interior, en cuanto persona investida de poder para ello, pronuncia la sentencia sobre felicidad o aflicción como consecuencias morales del acto. Dicha sentencia es inapelable por nuestra razón y sólo podemos respetar su aquiescencia o veto incondicionados. De acuerdo con Kant, «el veredicto de la conciencia moral sobre los hombres constituye una sentencia firme $a b s o$ lutoria o condenatoria; cabe observar que la primera nunca puede acordar una recompensa o premio, en cuanto ganancia de algo que anteriormente no era suyo, sino que sólo entraña un estar contento por haberse sustraído al peligro de ser encontrado culpable y esa dicha que comporta el reconfortante consuelo de la conciencia moral no es positiva —en cuanto júbilo-, sino únicamente negativa -el sosiego que sigue a la inquietud ${ }^{10}$.

Así pues, el dictamen absolutorio del tribunal kantiano de la conciencia moral equivale justamente a no ser encontrado «culpable» y no tener que responder, por lo tanto, a las acusaciones del implacable fiscal que todos llevaríamos dentro. La recompensa mediata o indirecta de tal absolución sería el encontrarse uno en paz consigo mismo. Si alguien pierde un dinero apostando en el juego, se podrá enfadar consigo mismo, pero, si lo gana haciendo trampas, terminará despreciándose a sí mismo, por mucho que celebre sus ganancias desde otro punto de vista muy diferente, nos advierte Kant en su Crítica de la razón práctica (1788) ${ }^{11}$, para subrayar los distintos raseros manejados por nosotros mismos cuando desempeñamos el papel de abogado defensor o de fiscal acusador en una causa donde somos al tiempo jueces y encausados. Al defensor le preocupa tan sólo nuestro bienestar y se atiene estrictamente al criterio de la felicidad propia; en cambio, el fiscal compara nuestro comportamiento con la ley moral e impone como castigo el autodesprecio, es decir, el que uno deje de hallarse satisfecho consigo mismo. Es más, este hallarse contento consigo mismo será definido por Kant como un «sentimiento moral» ${ }^{12}$ parangonable con el inquebrantable respeto que nos infunde la ley del deber ${ }^{13}$.

Tan peculiar sentimiento moral serviría como piedra de toque para compulsar lo que se corresponde, o no, con el deber. Para Kant, la ley moral no supone sino un condicional contrafáctico, el cual nos indica que podríamos habernos comportado de otra manera a como lo hemos hecho en un momento dado y también que sería posible oponerse a la presuntamente irremontable corriente de nuestras inclinaciones. En definitiva, nuestra conciencia moral nos haría cobrar consciencia de que podemos hacer algo porque debemos hacerlo así, tal como señala Kant en su segunda Crítica. El ejemplo con

\footnotetext{
${ }^{10}$ Cfr. I. Kant, Metafisica de las costumbres, Ak. VI, pp. 439-440, nota.

11 Cfr. I. Kant, Crítica de la razón práctica, Roberto R. Aramayo (ed.), Alianza Editorial, Madrid., 2000, p. 108; Ak. V, p. 37.

${ }^{12}$ Cfr. op. cit.., p. 111; Ak. V, p. 38.

13 Cfr. ibid., p. 172; Ak. V, p. 79.
} 
que Kant ilustra esta tesis es bastante llamativo y, para no desvirtuarlo con una mala glosa, prefiero citarlo literalmente: «Tomemos a cualquiera que considere irresistible su inclinación lujuriosa cuando se le presenta una ocasión propicia para ello y tenga delante al objeto amado e interroguémosle sobre lo que haría si ante la casa donde encuentra esa oportunidad fuera levantado un patíbulo para ahorcarlo nada más haber gozado de su voluptuosidad; ¿acaso no sabría dominar entonces su inclinación? No cuesta mucho adivinar cuál sería su respuesta. Pero preguntémosle ahora lo que haría si su príncipe, amenazándole con aplicarle sin tardanza esa misma pena de muerte, le exigiera levantar falso testimonio contra un hombre honrado al que dicho príncipe quisiera echar a perder recurriendo a fingidos pretextos; ¿acaso no le parecería entonces posible vencer su amor a la vida por muy grande que fuera éste? Quizá no se atreva a asegurar si lo haría o no; sin embargo, que le sería posible hacerlo, ha de admitirlo sin vacilar. Así pues, juzga que puede hacer algo porque cobra consciencia de que debe hacerlo y reconoce en su fuero interno a esa libertad que hubiese seguido siéndole desconocida sin la ley moral ${ }^{14}$.

Se diría que Kant ha tomado la primera parte del ejemplo de Rousseau, quien en el cuarto libro del Emilio (1762) dice lo siguiente: «No es cierto que la inclinación al mal sea invencible y que no seamos capaces de vencerla antes de haber tomado la costumbre de sucumbir a ella. Se dice que muchos hombres arrebatados por el amor compraron voluntariamente con su vida una noche de Cleopatra, y tal sacrificio no es imposible en la embriaguez de la pasión. Pero supongamos que el hombre más impetuoso y que menos domina sus sentidos viera el potro del suplicio, seguro de perecer atormentado en él un cuarto de hora después; cuán poco le costaría entonces resistir a las tentaciones; la espantosa imagen que las acompañaría le apartaría enseguida de dichas tentaciones y éstas, al verse rechazadas una y otra vez, se cansarían de volver. Siempre se tiene la fortaleza suficiente para hacer lo que uno quiere con vehemencia» ${ }^{15}$.

Ese potro de tortura que, según Rousseau, hubiera debido exhibirse ante los efímeros amantes de Cleopatra y aquel patíbulo que, según Kant, serviría de freno para el Don Juan más incorregible vienen a ejercer las funciones que, tanto el uno como el otro, encomiendan a la conciencia moral. En ambos casos la conciencia moral sancionará las infracciones del deber o de la virtud con el tormento del autodesprecio, esto es, con la irreparable pérdida de nuestra gozosa paz interior. Tal como explica Rousseau en la Profesión de fe del vicario saboyano (1762), cuando las pasiones nos arrastran y sucumbimos a ellas, el peor tormento es comprender que podríamos haber-

${ }_{14}$ Cfr. I. Kant, Crítica de la razón práctica, ed. cast. cit., pp. 96-97; Ak. V, p. 30.

15 Cfr. J.-J. Rousseau, Emilio, o de la educación, Mauro Armiño (ed.), Madrid, Alianza Editorial, 1998, p. 485; Oeuvres complètes, 5 vols., Bernard Gagnebin y Marcel Raymond (eds.), París, Gallimard, pp. 1959 ss., IV, pp. 650-651. 
nos resistido a las mismas ${ }^{16}$. «El supremo goce se cifra en el hallarse contento consigo mismo; es para merecer ese contento por lo que hemos sido puestos en la tierra y se nos ha dotado de libertad, por lo que somos tentados por las pasiones y retenidos por la conciencia ${ }^{17}$. También Kant definirá la moral como aquella teoría que nos hace dignos de ser felices, un merecimiento que por lo pronto le hace a uno sentirse satisfecho consigo mismo cuando es consciente de haber obrado virtuosamente ${ }^{18}$. La pena que puede imponer el tribunal de la conciencia será justamente arrebatarnos esa enorme autosatisfacción.

El gran paralelismo que se da entre los planteamientos de Rousseau y Kant, a propósito de sus respectivas concepciones en torno a la conciencia moral, no precisa ser enfatizado, porque se subraya por sí solo. La conciencia moral cuenta con una voz que haría «temblar incluso al criminal más audaz obligándole a esconderse ante su implacable mirada» ${ }^{19}$. «Todo hombre - escribe Kant- se encuentra en su razón con la idea del deber y se estremece al escuchar su voz inflexible en cuanto se hacen sentir las inclinaciones que le tientan a desobedecerla. Se halla convencido de que, aun cuando estas últimas se coaliguen para conspirar contra aquélla, la majestad de aquella ley que le prescribe su propia razón las dominará sin vacilar, saliendo así fortalecida su voluntad. ¿Qué es eso que hay en mí, capaz de hacer que pueda sacrificar los más sugestivos reclamos de mis instintos, así como todo deseo que tenga origen en mi naturaleza, en aras de una ley que no me promete ningún beneficio y cuya transgresión no entraña perjuicio alguno? Esta pregunta embarga el ánimo de admiración hacia la grandeza y sublimidad de esta disposición interna alojada en la humanidad, así como hacia la impenetrabilidad del enigma que la recubre; pues responder: "se trata de la libertad", sería caer en una tautología, dado que ésta representa el misterio mismo» ${ }^{20}$.

En esa singular corte de justicia que preside nuestra conciencia moral no hay lugar para las coartadas y si algo prueba su inapelable sentencia es que, desde un punto de vista ético, siempre somos libres por definición. «Un ser humano -nos dirá Kant en su segunda Crítica - puede rebuscar cuanto quiera al evocar cierto comportamiento contrario a la ley, para escenificarlo como un desliz inintencionado, como una simple imprevisión de la que no cabe nunca sustraerse por completo y, en definitiva, como algo a lo cual se vio arrastrado por el torrente de la necesidad natural, declarándose inocente por todo ello. Sin embargo, descubre que aquel abogado defensor, al hablar

\footnotetext{
${ }^{16}$ Cfr. op. cit., p. 416; OC, IV, p. 583.

17 Cfr. ibid., p. $420 ; O C$, IV, p. 587.

18 Cfr. I. Kant, Crítica de la razón práctica, ed. cast. cit., p. 231; Ak. V, p. 117.

19 Cfr. op. cit., p. 172; Ak. V, p. 80.

${ }^{20} \mathrm{Cfr}$. I. Kant, Acerca de un tono exaltado que recientemente se alza en filosofia, 1796, Ak. VIII, pp. 402-403.
} 
a su favor, no puede hacer acallar de ningún modo a ese fiscal acusador ubicado en su fuero interno, si es consciente de que cuando perpetró esa injusticia se hallaba en sus cabales, o sea, en el uso de su libertad y, aun cuando se explique su falta por cierta mala costumbre contraída mediante un paulatino descuido sobre uno mismo, e incluso llegue hasta el extremo de poder verla como una consecuencia natural del proceso recién descrito, todo ello no puede ponerle a salvo de la autocensura y los reproches que se hace a sí mismo» ${ }^{21}$.

Muy probablemente Kant está recreando una vez más esa lectura del Emilio (1762) de Rousseau que tanto impacto produjo sobre su reflexión moral. «En el fondo de todas las almas - había escrito Rousseau- existe un principio innato de justicia, previo a todos los prejuicios nacionales y a todas las máximas de la educación. Este principio es la regla involuntaria merced a la cual juzgamos nuestras acciones y las ajenas como buenas o malas, a pesar de nuestras propias máximas, y a este principio le otorgo el nombre de "conciencia"»" ${ }^{22}$.

La diferencia estriba en que Kant convertirá este «principio de justicia» en una «corte de justicia». En su Crítica de la razón práctica (1788) Kant se dirige a la conciencia tras el alias del deber, preguntándole: «iDeber! Tú que portas tan sublime e insigne nombre y haces acallar a todas las inclinaciones, ¿dónde se halla esa raíz de su noble linaje que repudia orgullosamente cualquier parentesco con las inclinaciones y de cuya estirpe desciende la condición indispensable del valor que únicamente los seres humanos pueden darse a sí mismos? ${ }^{23}$. Seguramente, al escribir estas líneas, Kant evocaba, también en esta ocasión, estas otras líneas de su maestro en materia moral: « $\mathrm{O}$ Oh conciencia! —había clamado el Rousseau de las Cartas morales-, instinto divino, voz inmortal y celeste, guía segura de un ser ignorante y limitado, pero inteligente y libre, juez infalible del bien y del mal, emanación sublime de la sustancia eterna, que vuelve al hombre semejante a los dioses, tú eres lo único que confiere a mi naturaleza cierta excelencia» ${ }^{24}$.

\section{El papel jugado por la culpa y los remordimientos en Rousseau}

Recordemos que, al entender de Kant, el agente moral debía compararse con el ser divino que porta en su fuero interno y que la sentencia del tribunal de la conciencia le podía despojar del valor que puede otorgarse a sí mismo: la

${ }^{21}$ Cfr. I. Kant, Crítica de la razón práctica, ed. cast. cit., pp. 198-199; Ak. V, p. 98.

${ }_{22}$ Cfr. J.-J. Rousseau, Emilio, ed. cit., p. 431; OC, IV, 598. Cfr. Cartas a Sofia, Alicia Villar (ed.), Madrid, Alianza Editorial, 1999, p. 123; OC, IV, p. 1108.

${ }^{23}$ Cfr. I. Kant, Crítica de la razón práctica, ed. cast. cit., p. 182; Ak. V, p. 86.

${ }^{24}$ Cfr. J.-J. Rousseau, Emilio, p. 434, y Cartas a Sofia, p. 127; OC, IV, pp. 600-601 y 1111. 
dignidad, lo cual le privaba del contento consigo mismo, esto es, de la propia estima. Pues bien, Rousseau pensaba exactamente lo mismo: «cuando únicamente nos ocupemos de comparar lo que hemos hecho con lo que hubiéramos debido hacer, será entonces cuando la voz de la conciencia recuperará su fuerza y su imperio; será entonces cuando la voluptuosidad pura que nace del contento de sí mismo y el amargo pesar por haberse envilecido distinguirán mediante unos sentimientos inagotables el destino que cada cual se habrá preparado» ${ }^{25}$. Quien desatiende los dictados de su conciencia se ve sentenciado a perder el contento consigo mismo y queda expuesto a verse devorado por los remordimientos, algo sobre lo cual Rousseau se muestra mucho más explícito que Kant, acaso por su propia biografía, como enseguida tendremos ocasión de comprobar.

«Se habla - leemos en el Emilio - del grito de los remordimientos que castiga en secreto los crímenes ocultos y viene a patentizarlos con suma frecuencia. ¡Ay! Quién de nosotros no ha conocido nunca esa importuna voz. Se habla por experiencia y se querría borrar ese involuntario sentimiento que nos granjea tantos tormentos. Mas obedeciendo a la naturaleza conoceremos con qué suavidad aprueba lo que ha ordenado y cuán encantada se halla el alma contenta de sí misma disfrutando con su paz interior. El malvado se teme y se rehúye, se distrae arrojándose fuera de sí, haciendo girar a su alrededor unos ojos inquietos y busca un objeto que le haga reír, pues estaría siempre triste sin la ofensa del sarcasmo; en cambio, la serenidad propia del justo es interior; su risa no es causada por la maldad, sino por un júbilo cuya fuente porta dentro de sí»» ${ }^{26}$.

Al final del segundo libro (redactado hacia 1766) de sus Confesiones (cuya primera parte fue publicada en 1787), Rousseau asegura haber escrito éstas para librarse de la pesada carga impuesta por los remordimientos y aliviar su conciencia de una falta cometida en su juventud. Se trata de una culpa que no había logrado confesar jamás a nadie, ni tan siquiera en la más estrecha de las intimidades. «Este peso - nos asegura - ha permanecido sin alivio alguno hasta hoy sobre mi conciencia, y puedo decir que el deseo de librarme de él ha contribuido mucho a la resolución que he tomado de escribir mis confesiones» ${ }^{27}$. Qué le hizo sentirse tan culpable a Rousseau, como para motivarle a redactar sus célebres Confesiones? Eso que él mismo califica de «acción atroz» consistió en robar una pequeña cinta y endosar la culpa del robo a otra persona, la joven y hermosa cocinera de una casa donde Rousseau trabajaba como lacayo en Turín cuando sólo contaba dieciséis años. Veamos el relato de los hechos que Rousseau nos brinda en las Confesiones (1766/1787).

${ }^{25}$ Cfr. J.-J. Rousseau, Emilio, p. 424, OC, IV, p. 59.

${ }^{26}$ Cfr. J.-J. Rousseau, Emilio, p. 430, y Cartas a Sofia, p. 122; OC, IV, pp. 597 y 1107.

${ }^{27}$ Cfr. J.-J. Rousseau, Las confesiones, Mauro Armiño (ed.), Madrid, Alianza Editorial, 1997, pp. 129-130; OC, I, p. 87. 
«Quisieron saber dónde había cogido la cinta. Me azoro, balbuceo y termino diciendo, mientras me ruborizo, que Marion es quien me la ha dado. Marion no sólo era bonita, sino que tenía una frescura y una dulzura que hacía que no se la pudiese ver sin amarla. Además de una chica buena, era sensata y absolutamente leal. Por eso se sorprendieron cuando dije su nombre. Llega ella, le muestran la cinta y yo la acuso descaradamente; ella se queda desconcertada, se calla y me lanza una mirada que habría desarmado al diablo en persona, pero que mi corazón resiste. Luego lo niega con rotundidad, pero sin arrebatarse, me increpa exhortándome a recapacitar y no deshonrar a una chica inocente que nunca me ha hecho mal alguno; yo, con una desvergüenza infernal, confirmo mi declaración y mantengo que me ha dado la cinta. La pobrecilla se pone a llorar y me musita entre sollozos estas palabras: " $\mathrm{A}$ Ah, Rousseau! Os creía bueno. Me hacéis muy desdichada, mas no me gustaría estar en vuestro lugar". Eso fue todo. Continuó defendiéndose con tanta sencillez como firmeza, pero sin permitirse la menor invectiva en contra mía. Esa moderación, que contrastaba con mi tono resuelto, la perjudicó. Se nos despidió a los dos, pronosticándose que la conciencia del culpable vengaría cumplidamente al inocente. Tal predicción no resultó vana, pues no ha dejado de cumplirse ni un solo día» ${ }^{28}$.

El remordimiento causado por esta mentira se hará insoportable para Rousseau. «Este recuerdo cruel - señala - me trastorna y me altera hasta el punto de ver en mis insomnios a esa pobre chica reprocharme mi crimen como si lo hubiera cometido ayer» ${ }^{29}$. Sin embargo, Rousseau intenta excusarse transfiriendo a Marion parte de tan onerosa culpa. Su belleza le turbaba y acusó a su amada imaginaria de haber hecho lo que él se proponía hacer, puesto que se había quedado con la cinta para entregársela luego a ella. La vergüenza de verse obligado a confesar públicamente aquella fechoría fue más fuerte que su posible arrepentimiento. Eso sí, reconoce que su inconmensurable aversión hacia la mentira obedece al pesar de poder haber cometido una tan malvada ${ }^{30}$.

Algunos años después, en el cuarto capítulo (1777) de Las ensoñaciones del paseante solitario (1782), Rousseau vuelve a subrayar la impronta dejada en su alma por esa mentira. «Esa criminal mentira que tuvo a la pobre Marion como víctima me ha dejado indelebles remordimientos, los cuales me han protegido el resto de mi vida contra toda mentira que pudiese afectar al interés y la reputación de algún otro. Ello me dispensó de distinguir entre la mentira perjudicial y la provechosa, pues encontrando culpables a las dos me prohibí ambas» ${ }^{31}$. Al escribir las Ensoñaciones en el ocaso de su vida, a

${ }^{28}$ Cfr. op. cit., pp. 129-129; OC, I, pp. 84-85. La cursiva es mía.

${ }^{29}$ Cfr. ibid.

${ }^{30}$ Cfr. Las confesiones, ed. cast. cit., p. 131; OC, I, p. 87.

${ }^{31}$ Cfr. J.-J. Rousseau, Las ensoñaciones del paseante solitario, Mauro Armiño (ed.), Madrid, Alianza Editorial, 1998, p. 73; OC, I, p. 1032. 
Rousseau le sigue atormentando «aquella espantosa mentira cometida en la primera juventud, cuyo recuerdo - asegura - me ha perturbado toda mi vida e incluso continúa durante mi vejez entristeciendo un corazón afligido por tantas otras cosas. Aquella mentira, que fue un enorme crimen en sí misma, debió serlo aún más por unos efectos que yo siempre he ignorado, pero que el remordimiento me ha hecho suponer tan crueles como era posible» ${ }^{32}$.

Rousseau siempre se sintió culpable por esta mentira con la cual responsabilizó a Marion de una fechoría que él había cometido. Si hemos de creer su testimonio, los remordimientos con que su conciencia sancionaban esa culpa le atormentaron durante toda su vida y le llevaron a pensar en escribir sus famosas Confesiones. En cambio, resulta curioso que no se sintiera igualmente culpable por haber abandonado a sus cinco hijos en la inclusa, es decir, por no haber cumplido con lo que Hans Jonas considera el paradigma o el arquetipo del concepto mismo de responsabilidad. «En la moral tradicional -escribe Jonas- encontramos un caso (que conmueve profundamente al espectador) de una responsabilidad y un deber elementales no recíprocos, que se reconocen y practican espontáneamente: la responsabilidad y el deber para con los hijos que hemos engendrado y que perecerían sin los cuidados que a continuación precisan. Es éste el único comportamiento totalmente altruista procurado por la naturaleza; de hecho el origen de la idea de responsabilidad no es la relación entre adultos autónomos (la cual es origen de la idea de los derechos y deberes recíprocos), sino esta relación -consustancial al hecho biológico de la procreación - con la prole necesitada de protección. Éste es el arquetipo de toda acción responsable, arquetipo que, felizmente, no precisa ninguna deducción a partir de un principio, sino que se halla poderosamente implantado por la naturaleza en nosotros (o, al menos, en la parte de la humanidad que da a luz)» ${ }^{33}$.

La escrupulosa conciencia moral de Rousseau, que tanto le atormentó por su conducta con Marion, se mostró en principio extraordinariamente laxa para con sus deberes paternos. Escuchemos los alegatos de su abogado defensor, acudiendo al octavo libro (que data de 1769) de las Confesiones (cuya segunda parte fue publicada en 1789): «Mientras que filosofaba sobre los deberes del hombre, un suceso vino a hacerme reflexionar mejor sobre los míos. Teresa quedó embarazada por tercera vez. Mi tercer hijo fue llevado al hospicio, igual que los dos primeros y lo mismo se hizo con los dos que siguieron; pues he tenido cinco en total. Este arreglo me pareció tan bueno, sensato y legítimo que si no me vanaglorié abiertamente del mismo fue únicamente por consideración hacia la madre, aun cuando sí se lo manifesté a todos cuantos había hecho partícipes de nuestras relaciones. Tras calibrarlo todo, elegí para mis hijos lo mejor o lo que yo creí tal. Yo habría querido, y todavía lo querría, haber sido educado y alimentado como ellos lo

${ }_{32}$ Cfr. op. cit., p. 64; OC, I, pp. 1024-1025.

${ }_{33}$ Cfr. H. Jonas, El principio de responsabilidad, Barcelona, Círculo de Lectores, 1994, p. 83. 
fueron» ${ }^{34}$. En un arrebato retórico, Rousseau sostiene que, «al entregar a mis hijos a la educación pública, creí hacer un acto de ciudadano y de padre, y me veía como un miembro de la República de Platón» ${ }^{35}$.

Sin embargo, el fiscal acude a la citación del tribunal de su conciencia y no deja de proclamar sus alegaciones. «Más de una vez - reconoce-, los pesares de mi corazón me han enseñado que yo estaba equivocado» ${ }^{36}$. Ahora bien, eso no significa exactamente que se arrepienta de su decisión ni se identifique con un padre irresponsable. Rousseau no habría pisoteado «sin escrúpulo el más dulce de los deberes. No, eso no es posible. Jamás, ni un sólo instante de su vida, Jean-Jacques ha podido ser un hombre sin sentimiento, sin entrañas, un padre desnaturalizado». Esto le parece sencillamente impensable, pues él no es insensible a la voz de su conciencia y se considera demasiado sincero consigo mismo como para querer desmentir con sus obras los principios morales que dicha conciencia le hace suscribir ${ }^{37}$. En realidad, él había examinado con detenimiento el destino de sus hijos y había elegido la opción que le pareció más aconsejable para ellos.

El noveno paseo de Las ensoñaciones (1778) vuelve a tratar este asunto y allí Rousseau transfiere nuevamente a otra persona parte de su culpa. Thérèse Levasseur, la madre de sus hijos, los habría echado a perder y la familia de ésta podría haberlos convertido en unos monstruos; ante semejante probabilidad, la educación menos peligrosa para ellos era la del hospicio y allí los metió. Lo contrario hubiera sido una irresponsabilidad por su parte y les hubiera granjeado un destino mil veces peor ${ }^{38}$. Rousseau no acepta que se le considere un padre desnaturalizado capaz de odiar a los niños y alega en su defensa la prueba de sus escritos, aduciendo que, «indudablemente, sería la cosa más increíble del mundo que la Nueva Eloísa (1760) y el Emilio (1762) fueran la obra de un hombre que no quiere a los niños» ${ }^{39}$.

Al margen de que acertase o no con dejar a sus hijos en el hospicio, lo cierto es que Rousseau supo rentabilizar los remordimientos de su conciencia y la culpa se convirtió en acicate para escribir obras tales como las Confesiones o el Emilio. Pero los admiradores del gran moralista no parecen haberle perdonado el no cumplir con ese paradigma de la responsabilidad que, según Hans Jonas, representan los deberes del padre hacia sus hijos y que sólo sería homologable con las responsabilidades asumidas por los políticos. Poco les importa que abandonar a los propios hijos en un hospicio fuese una costumbre muy extendida por la época, como indica el propio Rous-

\footnotetext{
${ }^{34}$ Cfr. J.-J. Rousseau, Las confesiones, ed. cast. cit., pp. 488 y 489-490; OC, I, pp. 356 y $357-358$

${ }^{35}$ Cfr. op. cit., p. 489; OC, I, p. 357.

${ }^{36}$ Cfr. ibid.

${ }^{37}$ Cfr. op. cit., p. 488; OC, I, p. 356.

${ }^{38}$ Cfr. J.-J. Rousseau, Ensoñaciones, ed. cast. cit., p. 139; OC, I, p. 1087.

${ }^{39}$ Cfr. op. cit., p. 140; OC, I, p. 1088.
} 
seau en el final del séptimo libro de las Confesiones ${ }^{40}$. Se diría que no puede aplicársele la misma vara de medir que a sus contemporáneos. Por ello algunos estudiosos de Rousseau invocan su presunta impotencia para tener hijos y otros apuntan a las acreditadas infidelidades de Teresa para poner en duda su paternidad ${ }^{41}$. Sin embargo, como hemos visto, Rousseau estaba convencido de que los hijos alumbrados por Teresa eran suyos y los remordimientos no dejaron de atormentarle finalmente, como testimonia el primer libro de su Emilio, donde se dirige así a sus lectores: «podéis creerme; a cualquiera que tenga entrañas y descuide tan sacrosantos deberes, le vaticino que durante largo tiempo verterá por su falta muy amargas lágrimas y nunca encontrará consuelo alguno» ${ }^{42}$.

Y ello fue así pese a todas las justificaciones con que pretendió eludir su responsabilidad. Dichas justificaciones quedaron compendiadas en una carta escrita el 20 de abril del año $1757^{43}$. Allí Rousseau se declara incapaz de mantener una familia con unos ingresos tan modestos y esporádicos que casi no alcanzan para sí mismo; eso sin contar que su trabajo no admite verse importunado por las preocupaciones domésticas o los cuidados de la prole, así como que su dolorosa enfermedad no le permitiría vivir demasiado tiempo. También estamos familiarizados ahora con otras muchas de las coartadas con que Rousseau fue salpicando sus escritos. Recordemos que la familia de Teresa suponía una grave amenaza para educar a sus hijos, quienes después de todo iban a correr mejor suerte viéndose confiados al Estado, tal como propusiera Platón en su República o que, a fin de cuentas, él se limitó a hacer lo mismo que muchas de las personas con quien trataba en un momento dado. Con todo, el fiscal acaba ganando la partida y el juez del tribunal de su conciencia lo encuentra culpable, dictando una sentencia condenatoria por mor de su irresponsabilidad. Los alegatos retóricos del elocuente defensor no han conseguido rebatir las pruebas presentadas contra el reo. Aunque a veces Rousseau quiso creer lo contrario, terminó por autoinculparse. Su conciencia le condena con la pérdida de su autoestima y ni siquiera sus inestimables obras lograron reconciliarle consigo mismo, puesto que su autosatisfacción se veía diezmada y carcomida por los remordimientos.

«Y es que - como bien señala Fernando Savater en su Ética para Amador-, al actuar mal y darnos cuenta de ello, comprendemos que ya estamos siendo castigados, pues no hay peor castigo que darse cuenta de que uno está boicoteando con sus actos lo que en realidad quiere ser» ${ }^{44}$. La fuente de donde manan los remordimientos no es otra que la libertad. «Por eso cuando sabemos que hemos hecho algo vergonzoso procuramos asegurar que no

\footnotetext{
40 Cfr. J.-J. Rousseau, Las confesiones, ed. cast. cit., pp. 470-471; OC, I, p. 344.

${ }^{41} \mathrm{Cfr} . O C, \mathrm{I}, \mathrm{pp} .1417 \mathrm{ss}$.

42 Cfr. J.-J. Rousseau, Emilio, ed. cast. cit., p. 58; OC, IV, pp. 262-263.

${ }^{43}$ Cfr. $O C$, I, p. 1431.

${ }^{44}$ Cfr. F. Savater, Ética para Amador, Barcelona, Ariel, 1991, pp. 111-112.
} 
tuvimos otro remedio que obrar así, que no pudimos elegir» ${ }^{45}$. Eso es lo que hace Rousseau con Marion y con Teresa, al intentar transferirles una culpa cuya paternidad - nunca mejor dicho - se resiste a reconocer. Para Savater uno de los rasgos que mejor definen a la conciencia es precisamente «renunciar a buscar coartadas que disimulen que somos libres y, por tanto, razonablemente responsables de las consecuencias de nuestros actos» ${ }^{46}$. El meollo de la responsabilidad no consiste sino en saber que somos libres, o sea, «que cada uno de mis actos me va construyendo, me va definiendo, me va inventando. Al elegir lo que quiero hacer voy transformándome poco a poco. Todas mis decisiones dejan huella en mí mismo antes de dejarla en el mundo que me rodea. Y claro, una vez empleada mi libertad en irme haciendo un rostro, ya no puedo quejarme o asustarme de lo que veo en el espejo cuando me miro» ${ }^{47}$.

\section{Schopenhauer y su alegato contra las coartadas de la responsabilidad}

$\mathrm{Si}$ - como hemos visto- Rousseau se agazapaba tras el escudo de la culpa, con el fin de transferir o difuminar sus responsabilidades ante las acusaciones vertidas por su conciencia moral, inclinándose siempre a oficiar como abogado defensor de sí mismo, hay otro pensador que mantuvo la tendencia justamente opuesta y, asumiendo más bien el papel de fiscal, quiso subrayar lo que nos acaba de recordar Fernando Savater, esto es, que la responsabilidad no admite coartadas de ninguna especie. Este pensador no es otro que Schopenhauer. Para el autor de Los dos problemas fundamentales de la ética (1841), todos tenemos un «sentimiento firme y claro sobre la responsabilidad por aquello que hacemos, un sentimiento relativo a la imputabilidad concerniente a nuestras acciones, lo cual descansa en la inquebrantable certeza de que somos los autores de nuestros actos» ${ }^{48}$.

Según Schopenhauer, nadie puede pretender disculpar y transferir su culpa hacia los motivos que condicionaron necesariamente su acción, pues las circunstancias hubiesen determinado un desenlace bien distinto si el sujeto hubiera sido de otra manera y tuviese otro carácter. Nuestras acciones no son sino testimonios de nuestro carácter y a éste, o sea, a lo que somos, es a quien hay que adjudicar la culpa o el mérito de nuestros actos. El sujeto moral «habría podido ser otro, y en aquello que dicho sujeto es reside tanto la culpa como el mérito, pues todo lo que hace se infiere de sí mismo como

\footnotetext{
45 Cfr. op. cit., p. 112.

46 Cfr. op. cit., p. 106.

47 Cfr. op. cit., p. 117.

48 Cfr. A. Schopenhauer, Los dos problemas fundamentales de la ética, Pilar López de Santa María (ed.), Madrid, Siglo XXI, 1993, p. 123; E 93. Reviso la traducción en todos los casos.
} 
un simple corolario. Por eso, aunque la responsabilidad moral del hombre se refiere primaria y ostensiblemente a lo que hace, en el fondo atañe a cuanto es. De que él, según se infiere de su acción, sea tal como es y no de alguna otra manera, es por lo que se siente responsable» ${ }^{49}$.

Y ahí sería donde vienen a enclavarse realmente los remordimientos, al entender de Schopenhauer. «Las recriminaciones de la conciencia moral se refieren, ante todo y ostensiblemente, a lo que hemos hecho, pero en realidad y en el fondo, a lo que somos, algo sobre lo cual sólo nuestros actos proporcionan un testimonio válido, al comportarse con respecto a nuestro carácter como el síntoma en una enfermedad» ${ }^{50}$. La conciencia moral no consiste sino en conocernos a nosotros mismos cada vez mejor, gracias a que vamos cumplimentando el expediente de los hechos. Operari sequitur esse, repite Schopenhauer una y otra vez. «En lo que hacemos conocemos aquello que somos» ${ }^{51}$, proclama Schopenhauer, convencido de que, tal como nos decía Savater, «la libertad sólo se revela a través de la responsabilidad».

Schopenhauer arremete contra esa metáfora kantiana que describe a la conciencia como un proceso judicial. Era un gran admirador de Kant y se creía el mejor continuador de sus doctrinas, pero también entendía que un aventajado discípulo tiene la obligación de mostrarse implacable con los errores del maestro. Por de pronto, «Kant se sirve de unas expresiones juridicas que, sin embargo, parecen muy poco apropiadas para reproducir las emociones más clandestinas del corazón humano. Pero ese lenguaje y esa presentación judicial se mantienen de principio a fin, hasta el punto de parecer algo propio y consustancial al tema en cuestión. En nuestro fuero interno se nos representa toda una corte de justicia, con proceso, juez, fiscal, defensor y sentencia. Si este procedimiento interno fuera realmente tal como Kant lo presenta, habría que asombrarse de que algún hombre pudiera ser, no ya $\tan$ malo, sino tan tonto, como para obrar en contra de la conciencia moral. Pues esa instancia de índole tan peculiar que parece casi sobrenatural, enclavada en el seno de nuestra autoconciencia, ese presunto y severo tribunal que se hallaría en la enigmática oscuridad de nuestro fuero interno, habría de intimidarnos tan atrozmente que nadie osaría contravenir su temible interdicción. Cuando en realidad sucede lo contrario y la eficacia de la conciencia moral es tan débil que todos los pueblos han procurado sustituirla por una religión positiva» 52 .

El problema, para Schopenhauer, es que Kant «atribuye al autoenjuiciamiento moral como algo consustancial una forma que no lo es propia en modo alguno y que puede amoldarse a cualquier otra reflexión, ajena por completo a la específicamente moral, sobre lo que hemos hecho y hubiéra-

\footnotetext{
${ }^{49}$ Cfr. op. cit., ed. cast. cit., p. 204; E 177.

${ }^{50}$ Cfr. op. cit., p. $281 ; \mathrm{E} 256$.

${ }_{51}$ Cfr.op. cit., p. 127; E 97.

s2 Cfr. op. cit., p. 198; E 170-171.
} 
mos podido hacer de otra manera» ${ }^{53}$. La comparecencia de un fiscal, un abogador defensor y un juez que dicte sentencia se darán también en un dictamen que tenga por fundamento una superstición o en cualquier meditación sobre un hecho intrascendente desde un punto de vista moral. «Si desnudamos a esa presentación kantiana de aquella dramaturgia jurídica con que la ha investido arbitrariamente, se disipa también el halo que la rodea junto a su majestuoso efecto y sólo queda el escueto hecho de que, al reflexionar sobre nuestras acciones, a veces nos asalta un descontento con nosotros mismos de índole muy peculiar, el cual tiene la peculiaridad de no concernir al resultado, sino a la acción misma, y de no descansar en razones egoístas, como sí lo hacen todas aquellas en que lamentamos la imprudencia de nuestro obrar. Nosotros estamos insatisfechos con nosotros mismos por un sufrimiento que no hemos padecido, sino causado; éste es el hecho desnudo y que nadie negará» ${ }^{54}$.

De ahí que Schopenhauer afirme rotundamente: «allí, donde radica la culpa, tiene que radicar también la responsabilidad, y éste es el único dato que nos habilita para inferir la libertad moral» ${ }^{55}$. Al contrario que Rousseau, para quien culpa y responsabilidad pueden andar cada una por su lado, Schopenhauer piensa que los remordimientos por un sufrimiento infligido a otro constituyen una piedra de toque fundamental para compulsar nuestro comportamiento ético, el cual no consiste sino en hacernos responsables de todos aquellos actos que tengan una significación moral, subrayando, eso sí, el hecho de que, con ello, estamos respondiendo de aquello que realmente somos. Por otra parte, pese a sus demoledoras críticas contra la metáfora kantiana del tribunal de la conciencia, Schopenhauer sí coincide con Kant en la significación moral de que uno se sienta insatisfecho consigo mismo. «El objeto de nuestra satisfacción o insatisfacción con nosotros mismos es aquello que somos, según haya prevalecido el egoísmo, la maldad o la compasión. Con arreglo a esa misma medida juzgamos igualmente a los demás; aquello que, al enjuiciarse uno a sí mismo, se manifestaba como satisfacción, o bien como una insatisfacción que puede llegar hasta el remordimiento de conciencia, se presenta aquí como elogio, aprobación o alta estima, o bien como censura, indignación o desprecio» ${ }^{56}$.

$\mathrm{Al}$ entender de Schopenhauer, el criterio para conferir un valor moral a nuestras acciones es que no se vean provocadas por motivos egoístas o interesados. Y la señal interna para certificar ese valor moral es que dichas acciones nos dejen «una certera satisfacción con nosotros mismos, o sea, eso que se ha dado en llamar aprobación de la conciencia moral, al igual que las acciones proclives a la injusticia y la crueldad hacen experimentar un auto-

${ }_{53}$ Cfr. ibid.

${ }^{54}$ Cfr. op. cit., p. 201; E 173-174.

${ }_{55}$ Cfr. op. cit., p. $123 ; \mathrm{E} 93$

56 Cfr. op. cit., pp. 281-282; E 256-257. 
enjuiciamiento interno enteramente adverso; además, como señal externa, secundaria y accidental, las acciones del primer tipo suscitan la aprobación y el respeto de los testigos imparciales, mientras que las de la segunda clase provocan lo contrario» ${ }^{57}$.

Una vez familiarizados con las posturas de Kant, Rousseau y Schopenhauer en torno a la conciencia moral, los remordimientos de la culpa y su conexión con la responsabilidad, les propongo examinar juntos un caso práctico, para comprobar qué rasero aplicaríamos nosotros mismos como testigos presuntamente imparciales del asunto en cuestión. Por eso, el cuarto hito de nuestro itinerario está formulado con una interrogante.

\section{4. ¿Acaso el padre de Diderot obró irresponsablemente al no destruir un testamento que consideraba inicuo?}

Tal como quedó anunciado al principio, para finalizar quisiera traer a colación un dilema moral experimentado realmente por el padre de Diderot y que éste relata en un breve opúsculo titulado Conversación de un padre con sus hijos (1771) ${ }^{58}$. Al parecer, el padre de Diderot era un hombre muy apreciado entre sus convecinos por su proverbial honestidad y esta merecida reputación le hacía oficiar habitualmente como albacea testamentario. En cierta ocasión le tocó hacer este papel, cuando murió un viejo párroco de una localidad cercana que, aparentemente, había fallecido sin expresar sus últimas voluntades respecto a su patrimonio. El difunto había sobrepasado los cien años y esa circunstancia le había permitido ahorrar una pequeña fortuna de unos cien mil francos. Esta suma había que repartirla entre los presuntos herederos, una docena de parientes que se hallaban sumidos en la más extrema indigencia. Sin embargo, mientras hacía el inventario de los bienes, nuestro albacea se topó un vetusto cofre que contenía un revoltijo de papelajos. Allí se habían almacenado antiquísimas facturas, pagarés caducados, viejas cartas y toda suerte de documentos, entre los que figuraba un testamento. Era tan antiguo que las personas designadas para ejecutarlo habían fallecido hacía ya más de veinte años. Este legajo lo trastocaba todo, pues instituía como legatarios universales a los miembros de una conocida y opulenta familia de libreros asentada en París, ignorando a esos indigentes que hubieran aliviado su enorme miseria gracias al reparto de la herencia entre los mismos.

Tremendamente afligido por las perversas consecuencias del inoportuno hallazgo, lo primero que se le ocurre al padre de Diderot es quemar ese inicuo testamento. Al fin y al cabo, sólo él tiene noticia de su existencia y su

${ }^{57}$ Cfr. op. cit., p. 229; E 204.

58 Cfr. D. Diderot, «Entretien d'un père avec ses enfants», en Le neveu de Rameau et autres dialogues philosophiques, Jean Varloot (ed.), Paris, Folio, 1972, pp. 251-175. 
autor parecía haberse olvidado del mismo al enterrarlo entre tantos legajos obsoletos. Está casi a punto de arrojarlo al fuego, cuando le invade la duda de si está tomando una decisión correcta. Tras deliberar largo rato con el papel en su mano delante de la chimenea, dejándolo acariciar una y otra vez por las llamas, opta por consultar el caso con un reputado sacerdote, célebre por ser una gran autoridad en materia de casuística. El casuista no deja de alabar su conmiseración hacia los pobres desheredados, pero cuestiona que alguien esté autorizado a interpretar las intenciones de un muerto y dictamina que debe proceder a ejecutar el testamento en cuestión.

Tan perplejo como estupefacto el padre de Diderot decide finalmente hacer venir al beneficiario del testamento e intenta convencerle, sin éxito alguno, de que se muestre generoso con los desheredados. Muchos años después, cuando relata este suceso a sus hijos, el padre de Diderot confiesa sentir hondos remordimientos por haber actuado como lo hizo. En ese momento, nuestro cronista, el propio Diderot, decide tomar la palabra para indicarle a su padre que debía haber seguido los dictados de su conciencia, en lugar de acatar ciegamente lo estipulado por las leyes, toda vez que con ello se perpetraba una grave injusticia. Pero el hermano de Diderot rechaza este argumento, aduciendo que todo juez debe cerrar los ojos ante las consecuencias de sus decisiones cuando aplican la ley, sacrificando el testimonio de su propia conciencia. Diderot le replica que la conciencia moral es anterior a cualquier ley jurídica y que, por lo tanto, se halla por encima en caso de mediar un conflicto entre ambas. La prueba es que su padre se siente culpable por haber acatado la ley, mientras desoía la voz de su propia conciencia.

A mí este dilema planteado por Diderot me ha interesado especialmente porque Kant recurre a un ejemplo muy parecido y nunca me ha dejado muy satisfecho su forma de ver las cosas. Kant, en la primera sección de Teoría y práctica (1793), nos propone imaginarnos lo siguiente. Alguien ha recibido la custodia de unos bienes cuyo propietario fallece inopinadamente, sin que sus herederos puedan llegar a saber por medio alguno nada del mencionado depósito. Y todo esto sucede justamente cuando aquel a quien se ha confiado dicho depósito atraviesa un desdichado trance personal. Una mala racha le ha llevado a la ruina total, siendo así que no tiene ninguna culpa en ese desastre financiero. Su mujer e hijos comienzan a verse agobiados por las privaciones, y el dinero del depósito es una suma considerable que serviría para sacarles inmediatamente de la penuria. Para más inri, nuestro protagonista es una excelente persona, mientras que los herederos disfrutan de un opulento patrimonio y son asquerosamente ricos, además de ser petulantes y manirrotos, de suerte que añadir ese importe a su inmensa fortuna sería tanto como arrojarlo directamente al mar. ¿Qué debe hacer el protagonista de semejante historia, dadas estas peculiares y apremiantes circunstancias? Kant lo tiene muy claro y nos dice que incluso un chaval de nueve años podría darnos una respuesta sin pensárselo dos veces. El dinero tendría que 
pasar a manos de los ricachones herederos del extinto dueño, porque lo contrario sería injusto y se opone al deber ${ }^{59}$. ¡Así de sencillo!

Yo me pregunto si el padre de Diderot no hubiera sido más responsable quemando un testamento que su conciencia consideraba totalmente inicuo. Confieso que albergo serias dudas con respecto a la respuesta dada por Kant para un caso bastante similar. Pero quiero dejar la interrogante abierta, para que cada cual se la responda dentro de su fuero interno, aunque tampoco quisiera ocultar mi simpatía hacia las observaciones hechas por Diderot en pro de la conciencia moral como instancia superior a toda ley.

Por lo que atañe a esas dos vertientes de la conciencia moral que se han querido examinar aquí, el remordimiento y la responsabilidad, lo cierto es que no me veo capaz de superar las definiciones acuñadas por Savater en su Etica para Amador y por eso voy a finalizar con ellas: «Lo que llamamos "remordimiento" - nos dice Savater - no es más que el descontento que sentimos con nosotros mismos cuando hemos empleado mal la libertad, es decir, cuando la hemos utilizado en contradicción con lo que de veras queremos como seres humanos. Y ser responsable es saberse auténticamente libre, para bien y para mal: apechugar con las consecuencias de lo que hemos hecho, enmendar lo malo que pueda enmendarse y aprovechar al máximo lo bueno» ${ }^{60}$.

\section{BIBLIOGRAFÍA}

ARAMAYo, Roberto R. (2001): Immanuel Kant. La utopía moral como emancipación del azar, Madrid, Edaf.

- (2001): Para leer a Schopenhauer, Madrid, Alianza Editorial.

BILBENY, Nobert (1994): Kant y el tribunal de la conciencia, Barcelona, Gedisa.

CASAlS, Jaume (1992): «La moral de la "Enciclopedia"», en Victoria CAMPS (ed.), Historia de la ética, vol. II, Barcelona, Crítica, pp. 168-193.

Cruz, Manuel, y ARAmayo, Roberto R. (coords.) (1999): El reparto de la acción. Ensayos en torno a la responsabilidad, Madrid, Trotta.

CRUZ, Manuel (1999): Hacerse cargo. Sobre responsabilidad e identidad personal, Barcelona, Paidós.

- (2000): «Responsabilidad, responsables y respondones», en M. J. BERTOMEU, R. GAETA y G. VIDIELla (eds.), Universalismo y multiculturalismo, Buenos Aires, Eudeba, pp. 57-80.

DIDEROT, Denis (1972): «Entretien d'un père avec ses enfants», en Jean VARLOOT (ed.), Le neveu de Ramau et autres dialogues philosophiques, París, Folio, pp. 251-275.

JoNAS, Hans (1994): El principio de responsabilidad, Barcelona, Círculo de Lectores.

KANT, Immanuel, (1988): Lecciones de ética, Roberto R. ARAMAYO (ed.), Concha Roldán (cotrad.), Barcelona, Crítica.

59 Cfr. I. Kant, Teoría y práctica, Roberto R. Aramayo y Manuel Francisco Pérez López (trads.), Madrid, Tecnos, 1986, p. 21; Ak. VIII, p. 286.

${ }^{60}$ F. Savater, op. cit., pp. 113-114. 
- (1989): La metafísica de las costumbres, Adela CoRTina (ed.), Jesús Conill (cotrad.), Madrid, Tecnos.

- (2000): Teoría y práctica, Roberto R. Aramayo (ed.), Manuel Francisco Pérez López y Juan Miguel Palacios (cotrads.), Madrid, Tecnos.

- (2000): Crítica de la razón práctica, Roberto R. ARAMAYo (ed.), Madrid, Alianza Editorial.

MonTaigne, Michel de (1998): Ensayos, Dolores PiCAzo y Almudena Montojo (eds.), Madrid, Cátedra.

MuguerZA, Javier (1994): «El tribunal de la conciencia y la conciencia del tribunal», Doxa, núm. 15-16, pp. 535-559.

Rousseau, Jean-Jacques: Oeuvres complètes, Bernard Gagnebin y Marcel RAYMOND (eds.), París, Gallimard, 5 vols., pp. 1959 ss.

- (1997): Las confesiones, Mauro ARMINo (ed.), Madrid, Alianza Editorial.

- (1998): Las ensoñaciones del paseante solitario, Mauro ARMiño (ed.), Madrid, Alianza Editorial.

- (1998) «Profesión de fe del Vicario Saboyano», en Emilio, o de la educación, Mauro ARMiÑo (ed.), Madrid, Alianza Editorial, Libro IV, pp. 396 ss.

- (1999): Cartas a Sofía, Alicia VILlar (ed.), Madrid, Alianza Editorial.

SAVATER, Fernando (1991): Ética para Amador, cap. VI, Barcelona, Ariel.

SCHOPENHAUER, Arthur (1993): Los dos problemas fundamentales de la ética, Pilar López de Santa María (ed.), Madrid, Siglo Veintiuno.

- (2000): Sobre la libertad de la voluntad, Ángel GABILONDo (ed.), Emilio Estiu (trad.), Madrid, Alianza Editorial.

- (2003): El mundo como voluntad y representación, Roberto R. ARAMAYo (ed.), Madrid, Fondo Cultura Económica/Círculo de Lectores. 